\title{
Improved Twin I-Girder Curved Bridge-Vehicle Interaction Analysis and Human Sensitivity to Vibration
}

\author{
Md. Robiul Awall ${ }^{1}$, Toshiro Hayashikawa ${ }^{2}$ and Tasnuva Humyra ${ }^{3}$ \\ 1. Department of Civil Engineering, Rajshahi University of Engineering and Technology, Rajshahi 6204, Bangladesh \\ 2. Faculty of Engineering, Hokkaido University, Sapporo 060-8628, Japan \\ 3. Department of Civil Engineering, Rajshahi Science and Technology University, Natore 6400, Bangladesh
}

\begin{abstract}
The perceptible vibration of curved twin I-girder bridges under traffic loads is an important design consideration, because this bridge have rather low torsional stiffness that produce excessive vibrations. The objective of this investigation was to study the vibration of curved twin I-girder bridges due to moving vehicles and the effect of vibrations on bridge users. To this end, a comprehensive three-dimensional finite element models for bridge and vehicle are developed by using ANSYS code for studying bridge-vehicle interaction and the resultant sensitivity to vibration. Truck parameters include the body, the suspension and the tires. Gap and actuator elements are incorporated into the tire models to simulate the separation between the tires and road surface, and road surface roughness, respectively. Road roughness profiles are generated from power spectral density and cross spectral functions. To couple the motion of the bridge and vehicle, Lagrange multipliers and constraint equations are utilized through the augmented Lagrangian method. A parametric study is performed to identify the effect of various parameters on the vibration of the bridge. The results have been expressed in the form of human perceptibility curves. This study finds that the bridge response is significantly influenced by the road roughness, bump height at expansion joint and vehicle speeds. The results show that the inclusion of features such as increasing the torsional stiffness by providing additional stiffened bracing has major effects on the reduction of perceptible vibration.
\end{abstract}

Key words: Perceptible vibration, bridge-vehicle interaction, torsional stiffness, finite element model, roughness, bottom bracings.

\section{Introduction}

Human sensitivity to vibration poses serious technical problems for engineers in various fields. In the field of transportation, there is concern for comfort in automobiles [1], civil aircraft [2] and in design of military aircraft for maximum efficiency [3]. One of the recent concerns of civil engineers has been the objectionable level of vibration on urban bridges used by pedestrians and vehicles. A bridge's vibration due to moving traffic is important for two reasons. First, the stresses are increased above those due to static and dynamic load applications. This is normally accounted for by the "impact factor" or "dynamic amplification factor" in the design $[4,5]$. The second reason is that

Corresponding author: Md. Robiul Awall, Ph.D., associate professor, research fields: structural dynamics and control, and bridge engineering. excessive vibration may be noticeable to persons on the bridge. The human body, however, is primarily sensitive to dynamic effects, such as acceleration and change of acceleration. Although not related to issues of safety, this may have the psychological effect of impairing public confidence in the structure. In cases where humans are disturbed by vibration of low frequency and large amplitudes, human reactions are basically physiological (low frequency and large amplitude vibrations are associated with sea sickness). On the other hand, in cases where a person is subjected to unexpected vibration, for instance, when a pedestrian on a bridge experiences whole body vibration due to traffic crossing the bridge, his reaction may be totally psychological. In such a case, a pedestrian may associate unexpected motion of the bridge with its poor design and possibly its failure, not knowing that this type of vibration is quite normal for 
the bridge, therefore, demands consideration at the design stage [6].

Literature related to human sensitivity to vibration was briefly reviewed by Guignard [7] and suggested that there is a need for more basic research into the factors determining human reaction to vibration of relatively low intensity and of the kind induced in structures excited by traffic. The perceptible vibration of multi span straight steel girder bridges under vehicle loads was studied by Moghimi and Ronagh [8]. They consider a simple model of vehicle, as well as road roughness and studied parametrically. However, the behavior of curved I-girder bridges is more complex and the curvature makes it complicated to perform numerical analyses compared with straight ones. Some studies of dynamic response of horizontally curved I-girder bridges have been performed for road vehicles in which multi-degrees-of-freedom vehicle models have been used in conjunction theoretical road surface profiles with some assumptions [9-12]. All of these researches referred above are focusing on multi I-girder bridges, while limited study was on horizontally curved twin I-girder bridges. Curved twin I-girder bridges have rather low torsional stiffness [13], because of not only the small number of their main girders but also the minimized crossbeams, lateral and sway bracing structures. This type of bridge may easily vibrate under external dynamic loads like moving vehicles, wind loads, etc. [14].

Past studies have shown that the dynamic response of a bridge depends on the dynamic properties of the vehicle, the dynamic properties of the bridge, and the bridge's pavement roughness. Vehicle properties include the self-weight, physical dimensions and mechanical properties of the suspension system and the tires. Bridge properties include the mass, flexural stiffness and span length. Some researchers suggest that other parameters, including the ratio of live load to dead load, tire stiffness and suspension stiffness, vehicle speed and bounce on suspension, also affect a bridge's dynamic response to the passage of a vehicle $[5,15]$. In theory, bridge response cannot be separated from the vehicle loading, since the response of a real bridge affects the wheel loads that initiate the original response. Therefore, an iterative analysis is required at each time step to ensure compatibility between the suspension, the bridge deflections and the interacting forces. In these cited studies, the interaction dynamics are treated as simple method and have some limitations because of geometric complexities of curved bridges. However, almost all of the analyses are local developed computer programs that were intended primarily for research use. In recent days, by using the powerful computers and the availability of advanced numerical methods, two- or even three-dimensional numerical modeling of bridge vibrations is within reach.

In the current studies, twin I-girder curved bridge-vehicle interaction dynamics and human perception to vibration are analyzed, based on FE (finite element) modeling by using commercially available ANSYS code. The objective of this investigation is to study the vibration of curved twin I-girder bridges due to moving vehicles and the effect of vibrations on bridge users. A parametric study is performed to identify the effect of various parameters on the vibration of the studied bridge. The results have been expressed in the form of human perceptibility curves (graphs of perceptible vibration acceleration versus vibration frequency). Based on the parametric study, several simple design rules are presented for the serviceability performances of steel curved twin I-girder bridges.

\section{Base Curve of Human Perceptibility}

Human are amazingly sensitive to vibration and are often disturbed by intensities that are well below those required to overstress the structures they inhabit or use [8]. Therefore, in the design of structures, human response to vibrations caused by frequent sources of dynamic loading, e.g., running vehicles or wind, 
should be regarded as a serviceability limit state. In general, several factors influence the level of perception and the degrees of sensitivity of people to vibration. Among them, one can note position of the human body, excitation source characteristics, exposure time, floor and deck system characteristics, level of expectancy and type of activity engaged in Refs. [16-18]. Higher values of vertical motion are acceptable in bridges, when compared to residential or office buildings, because users are out in the open and are more aware of the presence of wind or traffic. Furthermore, people crossing a bridge are exposed to vibration for short period of time.

Smith [19] presented the work of Irwin, who suggested a base curve for acceptable human sensitivity to vibration of a bridge shown in Fig. 1. According to the ISO (International Organization for Standards) [20], at vibration magnitudes below the relevant curve, complaints regarding vibration are rare, and, therefore, these magnitudes can be regarded as acceptable limit. A survey of users of highway bridges in the USA [19] indicated that, in the majority of cases, reports of disturbing vibration come from pedestrians. It appeared that the reason for this is that the drivers and passengers inside the vehicles seldom notice the oscillations of bridges, perhaps because their vehicle's normal vibration obscures these. It has been shown by Smith that pedestrians are less susceptible to the vertical component of vibration when walking than when standing [19]. A less stringent recommendation is suggested in the British standard for bridge design-BS 5400. Although it relates especially to footbridges, it can be applied to the footways of highway bridges as well. This standard is reasonably close to Irwin's suggested curve for storm conditions. In the current investigation, Irwin's curve for vertical component of bridge motion in stormy wind conditions is selected as a base curve for the human-perceptible vertical component of vibration on the footway of the bridge deck. Vertical component of time histories acceleration at a point on the footway are calculated to determine the corresponding root mean square (r.m.s.) acceleration, while the frequency is obtained by DFT (discrete Fourier transform).

These accelerations with corresponding frequency are then compared with the corresponding base curve shown in Fig. 1. Only if the calculated values lie below the respective base curve, is the criterion met.

\section{Numerical Models}

The numerical models for investigating the bridge-vehicle interaction dynamics are created by ANSYS code. It has numerous element types and especially an advanced contact technology, which is useful for the bridge-vehicle interaction analysis.

\subsection{Bridge Model}

In this study, horizontally curved steel twin I-girder bridge is adopted for discussion. It is simply supported at one end with roller bearings and at the other end with hinged ones. The span-length of the studied bridge is $50 \mathrm{~m}$ long. Two main I-girders of the studied bridge are spaced at $6.0 \mathrm{~m}$ apart transversely. The two main girders are interconnected by end- and intermediate-crossbeams at a uniform spacing of $5.0 \mathrm{~m}$. The deck slab is made of concrete of $10.5 \mathrm{~m}$ width and

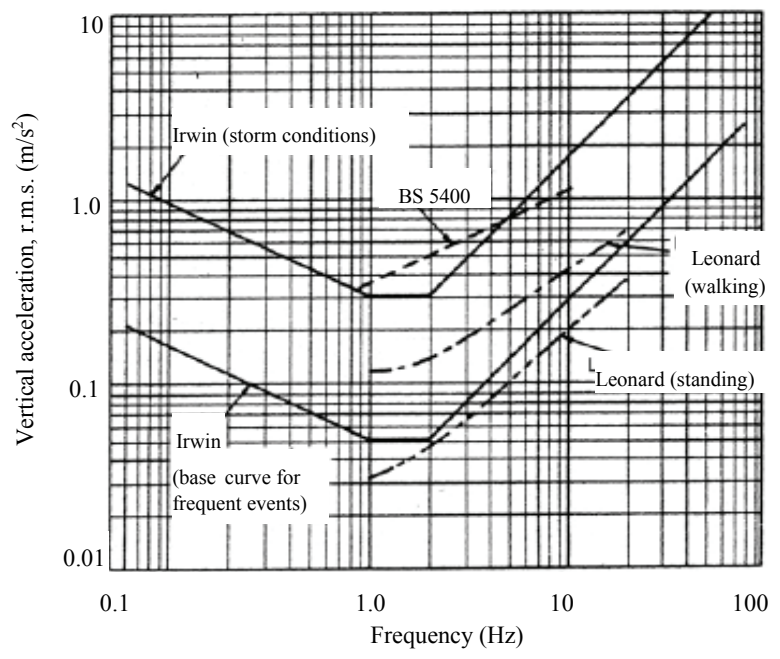

Fig. 1 Human response to the vertical component of bridge vibration [19]. 
$0.3 \mathrm{~m}$ thickness. Also, $3 \%$ super elevation is considered throughout the configuration of the bridge model.

Detailed FE models of the bridges are developed by using ANSYS code, as shown in Fig. 2. Hexagonal 8-node SOLID45 elements are used for the modeling of the concrete deck. This element has large deflection and large strain capability. All steel members are modeled by considering quadrilateral 4-node SHELL63 elements, which has large deflection capabilities. All the elements and boundary conditions are defined based on cylindrical coordinate system, whose origin is the centre of bridge's curvature.

\subsection{Vehicle Model}

AASHTO LRFD (Load and Resistance Factor Design) [21] design truck HS20-44 and design lane load are considered in this study. 3-D FE model of HS20-44 design truck is shown in Fig. 3. The model consists of five lumped masses with rotary inertias, representing the tractor, semi-trailer and three wheel/axle sets. Masses are connected by rigid beams and supported by spring-dampers. The upper spring-dampers represent the suspensions of the vehicle and the lower ones are for tires. Suspension force consists of the linear elastic spring force. The tire springs and all dampers are assumed to be linear. Properties of the masses and spring-dampers can be found in a report of Wang and Huang [22]. Gap elements are incorporated to the lower spring-damper elements to imitate the separation between tires and road surface. These gap elements are interconnected with actuators elements to simulate the effects of road roughness. The vehicle is assumed to move at constant speed on a circumferential path along the curved bridge deck. It can be seen that the vehicle model is capable to take into account the effects of pitching, rolling, and bouncing of vehicle body, as well as the effect of separations between tires and road surface.

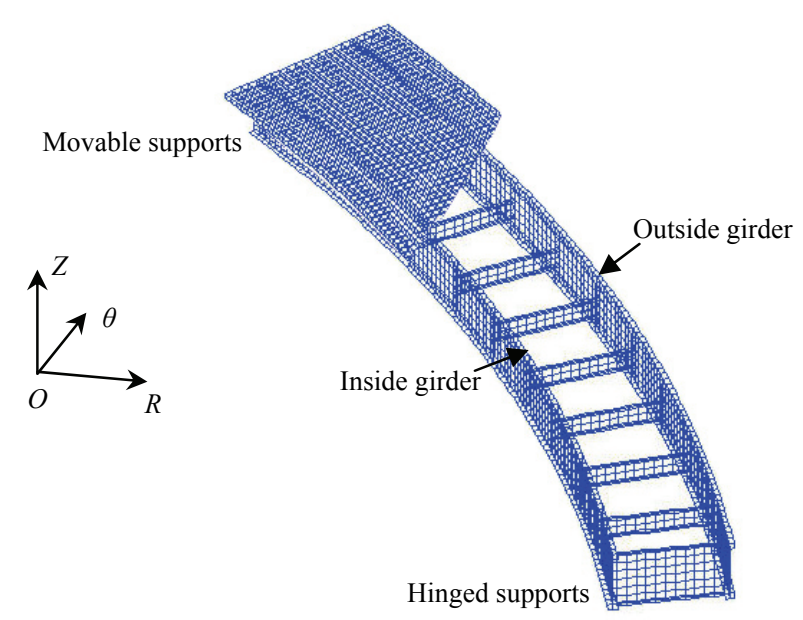

Fig. 2 Detailed finite element model of studied bridge.

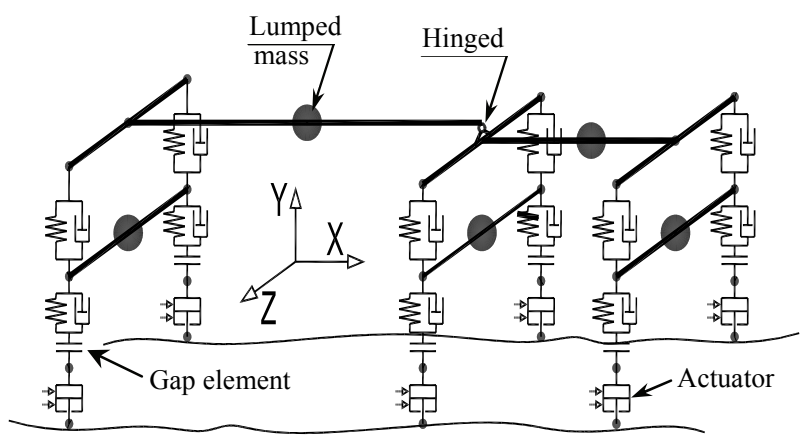

Fig. 3 Finite element model of HS20-44 design truck.

\subsection{Road Roughness Model}

In the bridge-vehicle interaction model, the road roughness must be modeled to analyze the effect of the road's surface roughness. Roadway surface profiles used in the dynamic response analyses are simulated by periodically modulated random processes that can be described by PSD (power spectral density) functions proposed by Dodds and Robson [23] and Honda et al. [24] as in Eq. (1):

$$
S(n)=S\left(n_{0}\right)\left(\frac{n}{n_{0}}\right)^{-w}
$$

where, $S(n)=\operatorname{PSD}\left(\mathrm{m}^{2} /\right.$ cycle $\left./ \mathrm{m}\right) ; n=$ wave number $($ cycle $/ \mathrm{m}) ; n_{0}=$ discontinuity frequency $=1 /(2 \pi)$ $($ cycle $/ \mathrm{m}) ; S\left(n_{0}\right)=$ roughness coefficient $\left(\mathrm{m}^{2} /\right.$ cycle $\left./ \mathrm{m}\right)$. 
According to the values recommended by Motor Industry Research Association [23], $S\left(n_{0}\right)=5 \times 10^{-6}$, $20 \times 10^{-6}, 80 \times 10^{-6}$ and $320 \times 10^{-6}$ for very good, good, average and poor road surfaces, respectively, are considered in this study. The value of $w$ is varied from 1.36 to 2.28 depending on the road state.

Correlated road surface profiles are generated from PSD and cross spectral density functions by assuming road surface as homogeneous and isotropic random process proposed by Dodds and Robson [23] and Sayers [25] as in Eq. (2):

$$
\begin{array}{r}
y_{R}(x)=\sum_{i=1}^{N}\left[\sqrt{\Delta n_{i} \cdot S_{x}\left(n_{i}\right)} \cdot \cos \left(2 \pi n_{i} x+\phi_{i}\right)+\right. \\
\left.\sqrt{\Delta n_{i} \cdot\left(S\left(n_{i}\right)-S_{x}\left(n_{i}\right)\right)} \cdot \cos \left(2 \pi n_{i} x+\theta_{i}\right)\right]
\end{array}
$$

where, $S_{x}(n)=$ cross spectral density; $x=$ longitudinal distance; $N=$ number of sinusoidal components; $n_{i}=$ spatial frequency; $\Delta n_{i}=$ bandwidth; $\varphi_{i}, \theta_{i}=$ first and second random phase angles, respectively. By using these equations, several road roughness profiles are generated for very good, good, average and poor roads. Typical good road roughness profile is shown in Fig. 4.

\subsection{Contact Model}

To couple the motion of the vehicle and bridge structure, contact technology is employed in this study. ANSYS node-to-surface contact pair consisting of a target surface mapped on the surface of deck element and contact elements connected with actuator

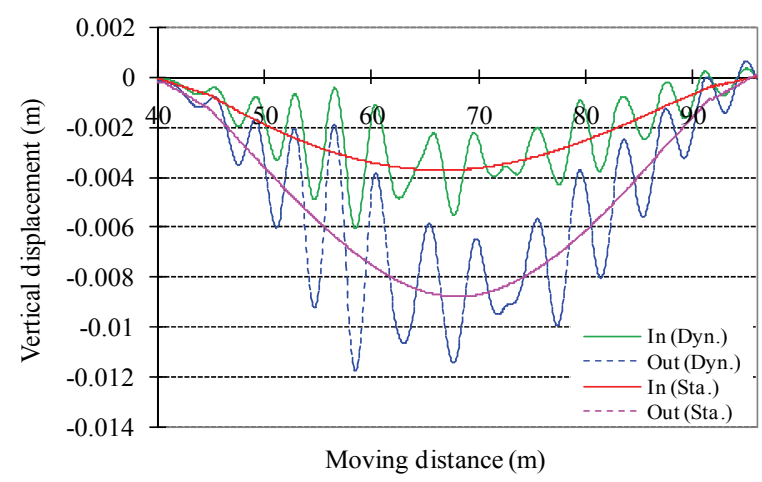

(a) elements are adopted. This contact technique allows contact nodes to slide on the target surfaces with or without friction. Isotropic coulomb friction is considered to the analysis. Lagrange multipliers and kinetic constraint equations between these systems are utilized by using augmented Lagrangian method; which is an iterative series of penalty updates to find the Lagrange multipliers. This method is selected over others such as pure penalty, pure Lagrangian multiplier methods because it usually leads to better conditioning and is less sensitive to the magnitude of the contact stiffness coefficient while introduces no additional equations to the discrete system [26].

\section{Effect of Various Parameters on Human Response}

In a curved bridge, outside girder vibration is always larger than the inside one shown in Fig. 5. This figure shows deflection and acceleration at mid span

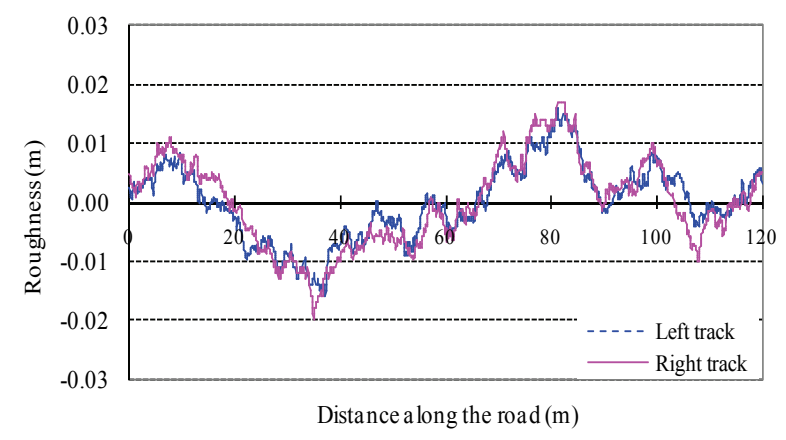

Fig. 4 Typical good road roughness profile.

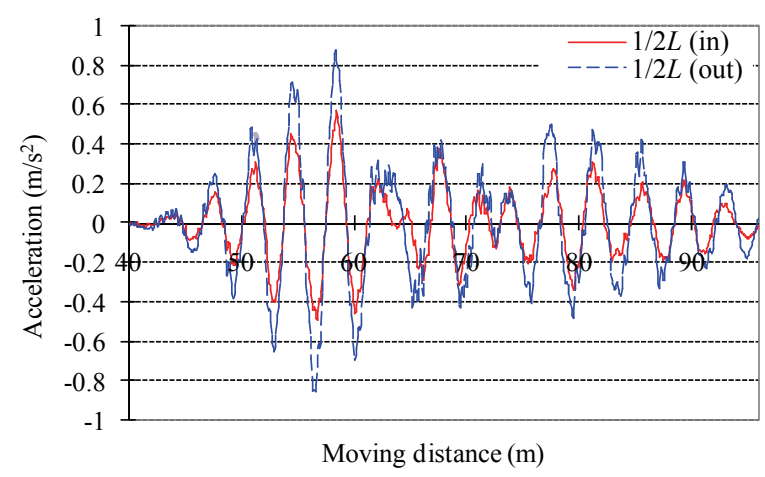

(b)

Fig. 5 Response of mid span girders with $30 \mathrm{~km} / \mathrm{h}$ vehicle velocity and average roughness conditions: (a) vertical displacement; (b) vertical acceleration. 
under vehicle moving on outside lane with $30 \mathrm{~km} / \mathrm{h}$ speed and average road roughness conditions. When the vehicle traveled closer to the sidewalk, the bridge section underwent a coupled mode consisting of torsional and vertical vibration and it is larger in outside girder in curved bridge. Decreasing radius of curvature means shortening the length of inside girder and lengthening that of the outside one, which is the reason why the inside girder is stiffer than the outside one. To study the bridge vibration, its dynamic response including deflection, acceleration of mid span of girder was considered. Since the girders are near the sidewalks and outside girder vibration is larger than the inside one, therefore outside girder vibration is of interest.

Based on the dynamic model introduced earlier, a comprehensive parametric study was performed to identify the effect of various parameters on the dynamic response of a composite steel twin I-girder bridge. To investigate the effect of each parameter on the human response, the results have been drawn on the human perceptibility curves similar to the curves depicted in Fig. 1. In this study, as mentioned earlier, Irwin's storm condition curve was selected as the base curve for the human perceptible vibration on the bridge sidewalk.

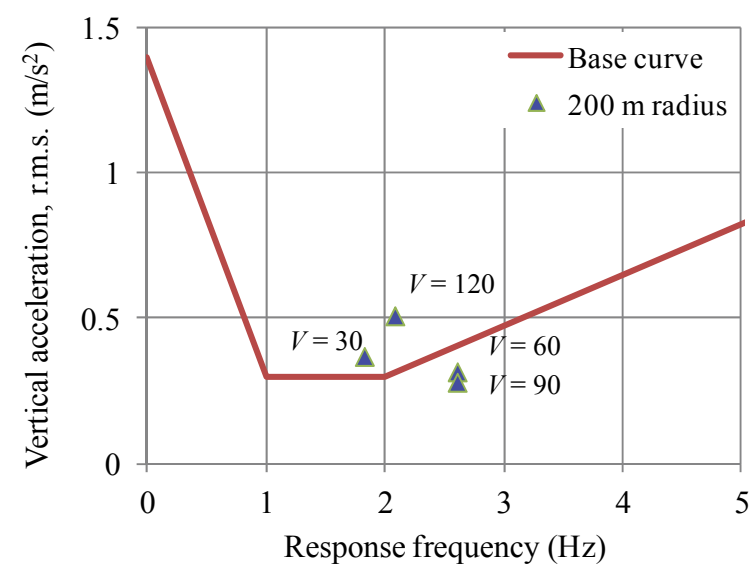

(a)

\subsection{Vehicle Velocity}

To study the effect of vehicle velocity, vehicle was moved on outside lane at different speeds with good road surface roughness conditions. The effect of vehicle speed on perceptible vibration of $200 \mathrm{~m}$ and $400 \mathrm{~m}$ radiuses of curvature are shown in Fig. 6 . These graphs contain the vertical component of acceleration of the bridge at the mid span of outside girder for different traveling speeds of the vehicle. Each point depicted on the graph shows acceleration and a frequency of occurrence. Analysis results show that at highest speed $(V=120 \mathrm{~km} / \mathrm{h})$ of vehicle produces higher responses. However, bridge response is larger at $30 \mathrm{~km} / \mathrm{h}$ vehicle speed than the $60 \mathrm{~km} / \mathrm{h}$ and $90 \mathrm{~km} / \mathrm{h}$ vehicle speeds, because in $30 \mathrm{~km} / \mathrm{h}$ speed dynamic response is dominated with combined effect of vehicle second mode (pitching) and first vertical mode of the bridge [27]. As it is seen in this figure, as the different speed of the vehicle, different vibration acceleration as well as different vibration frequency is induced due to torsional vibration effect of twin I-girder bridge. For this particular bridge, it is obvious that the perceptible vibrations are comfort levels when trucks travel at up to $90 \mathrm{~km} / \mathrm{h}$ speeds. Imposing a speed limit (proposed by some of the authorities in

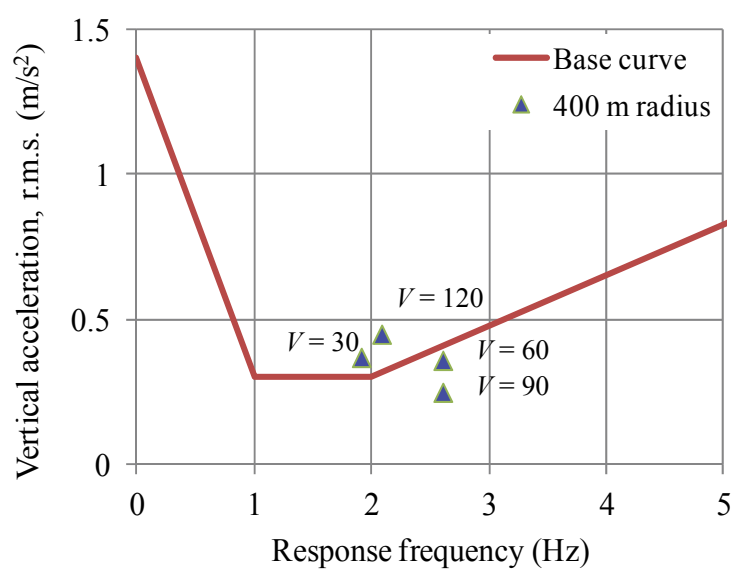

(b)

Fig. 6 Effect of vehicle velocity with good roughness conditions: (a) $200 \mathrm{~m}$ radius bridge; (b) $400 \mathrm{~m}$ radius bridge. 


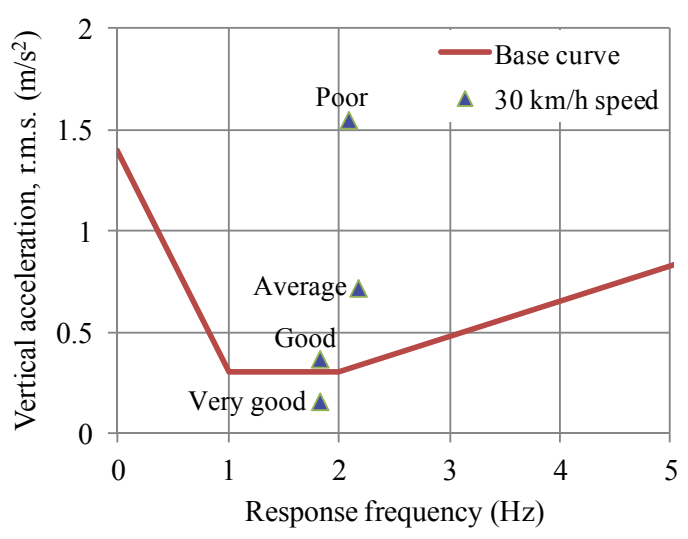

(a)

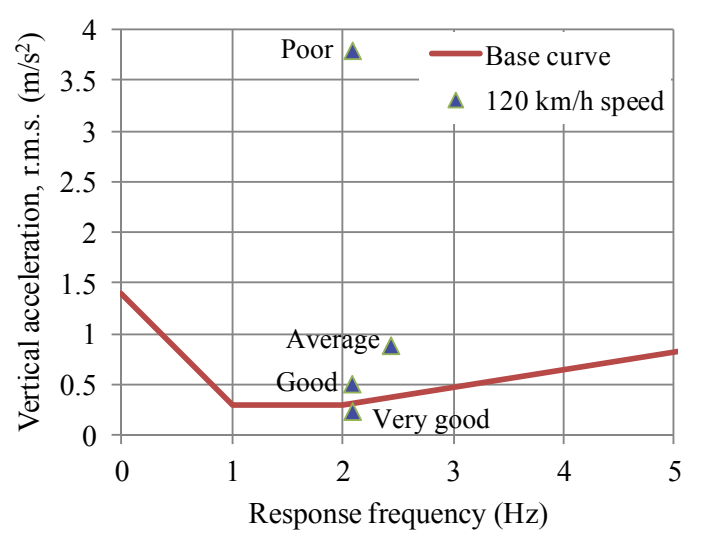

(b)

Fig. 7 Effect of road roughness conditions with different vehicle speeds: (a) $30 \mathrm{~km} / \mathrm{h}$; (b) $120 \mathrm{~km} / \mathrm{h}$.

charge) is, therefore, ruled out as a means of remediation, although felt necessary until more effective measures were in place.

\subsection{Road Roughness}

An important factor affecting the dynamic response of bridge-vehicle interaction system is road surface roughness. Four roughness classes, namely very good, good, average and poor along with different vehicle speeds are analyzed to clarify its effect on perceptible vibration. Outside lane loading and $200 \mathrm{~m}$ radius of curvature are considered of every analysis. The effects of road roughness on perceptible vibration of $30 \mathrm{~km} / \mathrm{h}$ and $120 \mathrm{~km} / \mathrm{h}$ vehicle speeds and $200 \mathrm{~m}$ radius of curvature are shown in Fig. 7. From the figure, it can be seen that, with the increasing of road surface roughness, the acceleration at all the cases increase distinctly. The acceleration value of very good roughness condition is lie below the base curve. However, in $30 \mathrm{~km} / \mathrm{h}$ vehicle speed, the acceleration value of good roughness condition is lie on the base curve, because in this case dynamic response is dominated with combined effect of vehicle and first vertical mode of the bridge [27]. In all roughness conditions, accelerations are larger at the fastest studied speed of $120 \mathrm{~km} / \mathrm{h}$. In a new bridge, road surface condition is good, however after several years, roughness is increasing and corresponding perceptible vibration also increase. Therefore, frequently maintenance of bridge deck is necessary to keep the good roughness condition for the better serviceability performance of the studied bridge.

\subsection{Radius of Curvature}

Effect of radius of curvatures on the human response are investigated by considering four types of radius of curvature $(r=100 \mathrm{~m}, 200 \mathrm{~m}, 400 \mathrm{~m}$ and $800 \mathrm{~m})$ with minimum and maximum studied velocities $(V=30 \mathrm{~km} / \mathrm{h}$ and $V=120 \mathrm{~km} / \mathrm{h})$ and considering good road surface roughness are shown in Fig. 8. This figure shows the effect of radius of curvature on perceptible vibration is low, that is acceleration value dose not very so much with varying radius of curvatures. However, $100 \mathrm{~m}$ radius bridge produces comparatively small acceleration value than others curvature of both studied vehicle speed. Also, the related frequency of $100 \mathrm{~m}$ radius bridge is comparatively smaller than others curvature of both studied vehicle speed. Because, in $100 \mathrm{~m}$ radius of curvature bridge torsional vibration is dominated more than the vertical vibration due to larger outer girder length and smaller inner girder length [27]. Except the $100 \mathrm{~m}$ radius bridge, as the radius of curvature decreases, little increase in the vibration acceleration is induced while the vibration frequency is little affected. For this particular bridge, it is obvious 


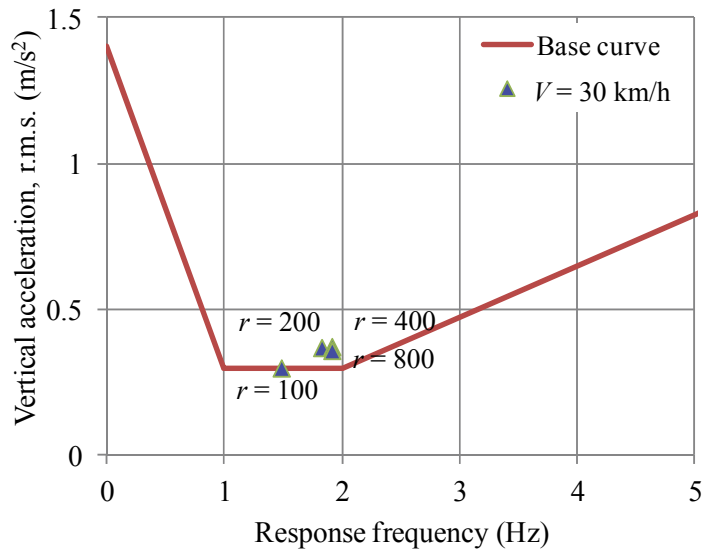

(a)

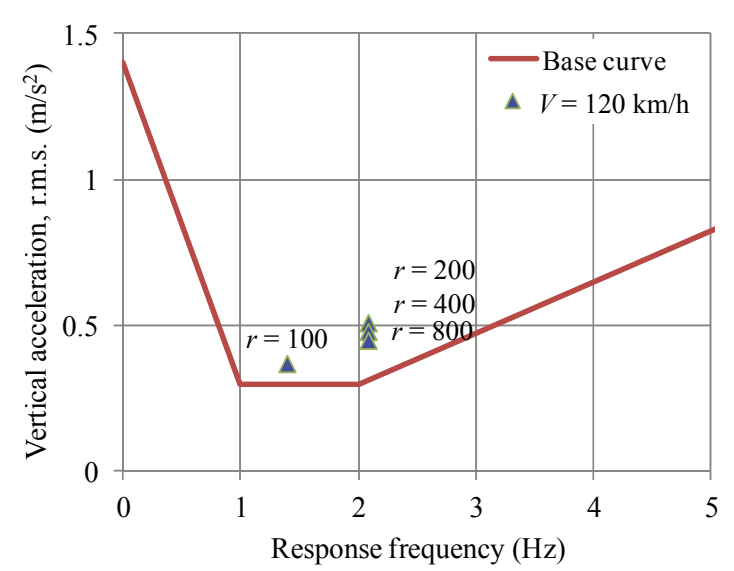

(b)

Fig. 8 Effect of radius of curvature: (a) $30 \mathrm{~km} / \mathrm{h}$ vehicle speed; (b) $120 \mathrm{~km} / \mathrm{h}$ vehicle speed.

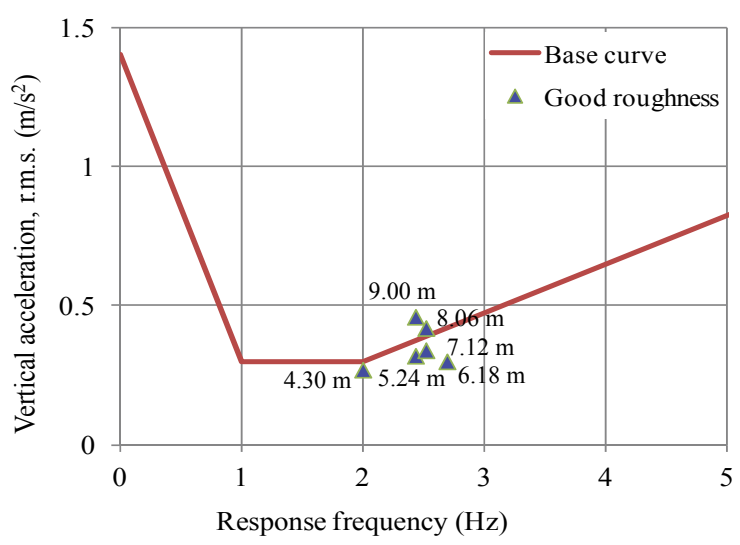

Fig. 9 Effect of vehicle lengths.

that the perceptible vibrations lie comfortable in $100 \mathrm{~m}$ radius bridge for low speed. However, other radius of curvatures, the perceptible vibrations are beyond comfort levels, even when vehicle travel at low speed.

\subsection{Vehicle Length Effect}

As AASHTO HS20-44 vehicle, the spacing between the two rear axles can be varied between $4.3 \mathrm{~m}$ and $9.0 \mathrm{~m}$ to produce unfavorable effects. In this study, six different axle spacing between the two rear axles ranging from $4.3 \mathrm{~m}$ to $9.0 \mathrm{~m}$ are analyzed. The result for $90 \mathrm{~km} / \mathrm{h}$ vehicle speed with good roughness condition is shown in Fig. 9. It should be noted that acceleration increases with the increase of rear axle spacing; Whereas, the frequency is different for different axle spacing. That is the characteristics of vehicle are changed accordingly with each axle spacing to keep the weight distributions on tires unchanged. In the study bridge, it is obvious that the perceptible vibrations are comfort levels for the rear axle length is below $8 \mathrm{~m}$. Imposing a vehicle length that is vehicle type (proposed by some of the authorities in charge) is therefore ruled out as a means of remediation.

\subsection{Bump Height at Expansion Joint}

In general, bridge road profiles, such as those occurring at movement joints or those caused by the settlement of the approach road, may have dominant effects on bridge response. Many complaints about the riding comfort usually involve abruptly bumps when vehicle entering or leaving bridges. Field observations indicate that the area on the top of abutments, next to expansion joints is usually damaged causing changes on the road surface. This section tries to establish correlations of bump heights, roughness classes, vehicle speeds with perceptible vibration level to help design engineers develop a serviceability performance.

To analyze the effect of bump heights on perceptible vibration, three different bump heights are investigated for parametric study namely $h=2 \mathrm{~cm}$, 
$h=4 \mathrm{~cm}$ and $h=6 \mathrm{~cm}$. Another model without bump is also considered to clarify the effect of bumps. The studied bridge is considered $400 \mathrm{~m}$ radius of curvature and vehicle is run on outside lane with $30 \mathrm{~km} / \mathrm{h}$ speeds. The perceptible vibration level for different bump heights and different road roughness conditions are shown in Fig. 10. From this figure, it can be seen that acceleration values are increasing with increasing bump heights, while the vibration frequency is little affected. At this almost constant frequency, it is true to say that the perception of vibration is related to the bump height. The higher the bump height, the higher the vibration will be felt.

Also different acceleration values are obtained for different roughness conditions and little effect on corresponding frequency. Of course, the poor roughness condition has higher acceleration value and very good roughness has lower acceleration value. That is, worse the road roughness is, larger the vibration is felt. For the studied bridge, it is obvious that the perceptible vibration is greatly affected on bump heights. Therefore, frequently bridge maintenance is needed to reduce the bump height at expansion joint in appropriate level. Also extra care should be taken to construct the approach slab next to expansion joint so that settlement of approach slab and damage of expansion joint will be reduced in reasonable level.

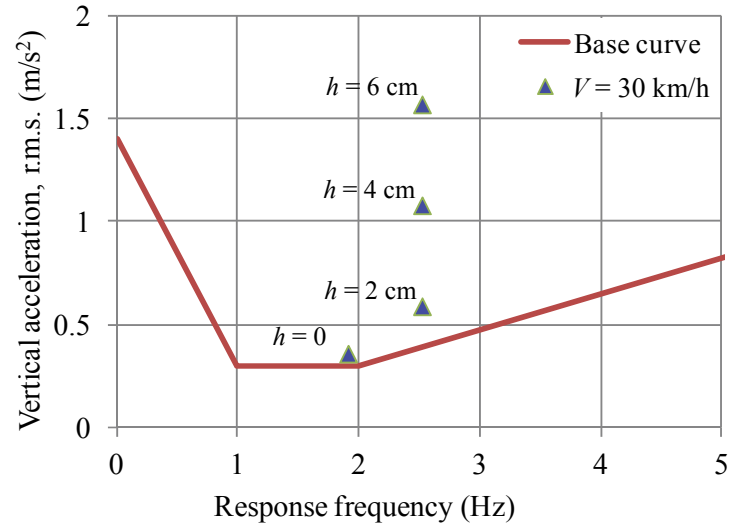

(a)

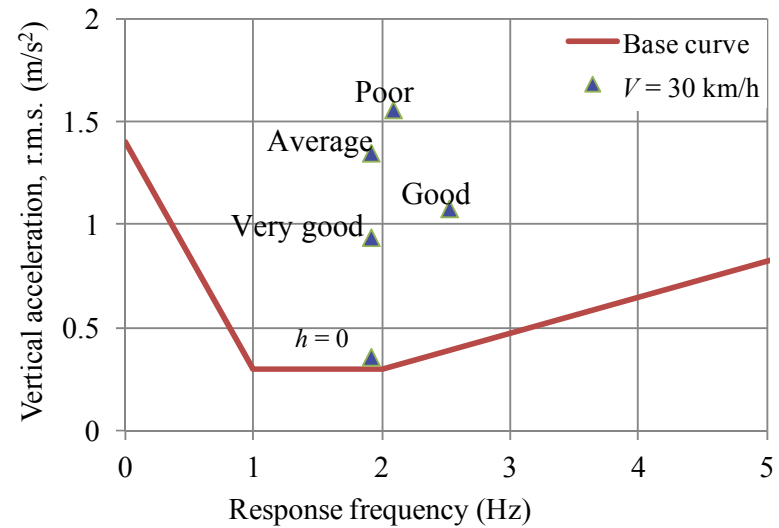

(b)

Fig. 10 Bump height effect with different roughness conditions: (a) bump height effect; (b) roughness effect with $4 \mathrm{~cm}$ bump.

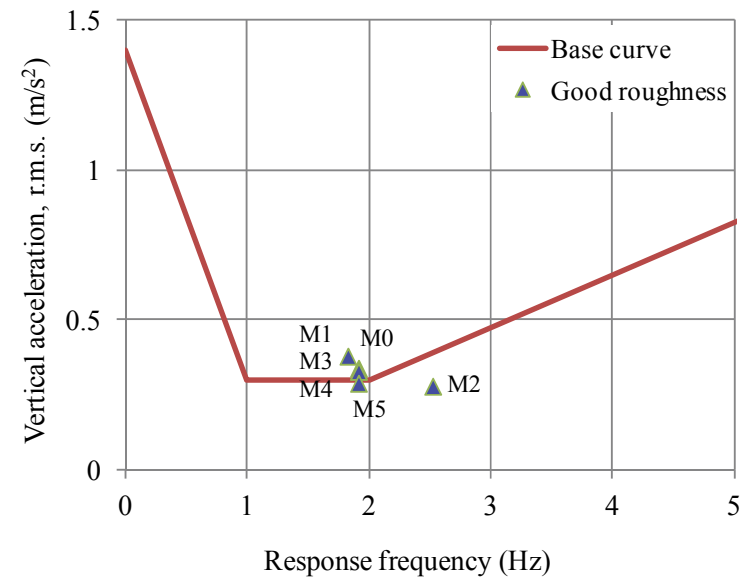

(a)

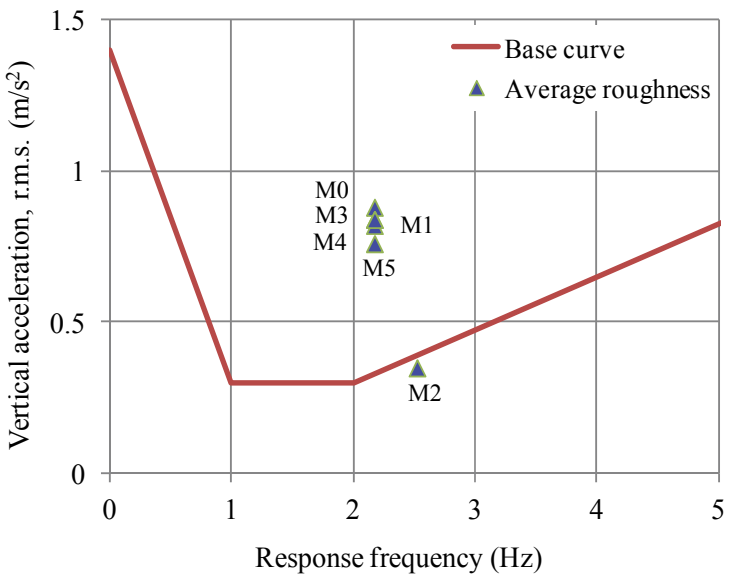

(b)

Fig. 11 Effect of bottom bracings for: (a) good roughness condition; (b) average roughness condition. 


\subsection{Bottom Bracing Effect}

The effects of bottom bracings are studied through five types of bottom bracing configurations. Model $\mathrm{M} 1$ is the "V" shaped diagonal bottom bracing system using I-shaped steel members of $0.5 \mathrm{~m}$ depth. Model M2, M3 and M4 are the " $\mathrm{X}$ " shaped bottom bracings uses $\mathrm{T}$-section steel members of the same dimension as Model M1, while bracing bays are different for each model. M5 is a bottom plate system using $20 \mathrm{~mm}$ thick steel plates in the plane of bottom flanges connected with the full height intermediate crossbeams. There are totally four exterior bays braced by bottom plates equally aligned at both ends of this model.

Note that by providing bottom bracings, responses are reduced from the original model (M0) as shown in Fig. 11; That is torsional stiffness increase significantly after providing bottom bracings. For good roughness conditions, M2 and M5 models acceleration are lie below the base curve and for average roughness conditions M2 model acceleration is lie below the base curve. That is among all models, M2 model exhibit better dynamic performance, because in this model, one T-section steel member is attached to the lower part, and the other inverted T-section steel member is just attached to the upper part of the first member, while the touching portion are rigidly jointed. That is why this type of bottom bracing is much stiffer and remarkably reduced dynamic vibration.

\section{Conclusions}

This paper investigated the vibration of curved twin I-girder bridges due to moving vehicles and the effect of vibrations on bridge users, based on numerical simulation of bridge-vehicle interaction. With respect to the results obtained from the previous sections, the following conclusions can be drawn.

Different vibration acceleration and frequency are obtained at different vehicle speed due to torsional vibration effect of twin I-girder bridge. For this particular bridge, it is obvious that the perceptible vibrations are comfort levels when trucks travel at up to $90 \mathrm{~km} / \mathrm{h}$ speeds. Imposing a speed limit is therefore ruled out as a means of remediation.

Bridge response is significantly influenced by road roughness, i.e., as the road roughness increases, dynamic response also increases. In a new bridge deck roughness is usually good; however after several years using the bridge deck, road roughness is increasing and corresponding perceptible vibration also increase. Therefore frequently maintenance of bridge deck is necessary to ensure the good roughness for the better serviceability performance of the bridge.

It was found that the effect of radius of curvature on perceptible vibration is low. For this particular bridge, it is obvious that the perceptible vibrations lie comfortable in $100 \mathrm{~m}$ radius for low speed. However, other radius of curvatures, the perceptible vibrations are beyond comfort levels, even when vehicle travel at low speed. Also, the perceptible vibrations are comfort levels for the two rear axles spacing up to the $8 \mathrm{~m}$. Therefore imposing a vehicle type is ruled out to keep good serviceability performance.

The defects at expansion joint greatly impact on the perceptible vibration of the studied bridge. Almost constant frequency, it is true to say that the perception of vibration is only related to the bump height. The higher the bump height, the higher the vibration will be felt. Therefore, frequently bridge maintenance is needed to reduce the bump height at expansion joint in appropriate level. Also extra care should be taken to construct the approach slab next to expansion joint so that settlement of approach slab and damage of expansion joint will be reduced in reasonable level.

It was found that perceptible vibrations are reducing by providing bottom bracing, due to increasing the torsional stiffness. Among all the studied models, M2 model gives better performance for reducing the perceptible vibrations. Therefore, bridge designer should pay attention to this phenomenon and consider 
the suitable bottom bracing system to minimize the perceptible vibrations of studied bridge.

\section{References}

[1] Janeway, R. N. 1947. Passenger Vibration Limits. Warrendale: Society of Automotive Engineers.

[2] McFarland, R. A. 1953. Human Factors in Air Transportation: Occupational Health and Safety. New York: McGraw-Hill.

[3] Getline, G. L. 1955. "Vibration Tolerance Levels in Military Aircraft." In Supplement to Shock and Vibration Bulletin, Vol. 22. Washington, D.C.: US Department of Defense, Research and Development.

[4] AASHTO (American Association of State Highway and Transportation Officials). 1996. Standard Specification for Highway Bridge. Washington, D.C.: AASHTO.

[5] Subcommittee on Vibration Problems Associated with Flexural Members of Transit System. 1985. "Dynamic of Steel Elevated Guide Ways-An Overview.” Journal of Structural Engineering, ASCE 111: 1873-9.

[6] Biggs, J. M. 1964. Introduction to Structural Dynamics. New York: McGraw-Hill.

[7] Guignard, J. C. 1971. "Human Sensitivity to Vibration." Journal of Sound and Vibration 15 (1): 11-6.

[8] Moghimi, H., and Ronagh, H. R. 2008. "Development of a Numerical Model for Bridge-Vehicle Interaction and Human Response to Traffic-Induced Vibration." Engineering Structures 30: 3808-19.

[9] Powell, G. H., and Mondkar, D. P. 1978. "Curvbrg: A Program for Analysis of Curved I-Girder Bridges." Computers \& Structures 9 (3): 255-63.

[10] Huang, D., Wang, T. L., and Shahawy, M. 1995. "Dynamic Behavior of Horizontally Curved I-Girder Bridges." Computers \& Structures 57 (4): 703-14.

[11] Barr, P. J., Yanadori, N., Halling, M. W., and Womack, K. C. 2007. "Live-Load Analysis of a Curved I-Girder Bridge." Journal of Bridge Engineering 12 (4): 477-84.

[12] Linzell, D. G., and Nadakuditi, V. P. 2011. "Parameter Influencing Seismic Response of Horizontally Curved, Steel, I-Girder Bridges." Steel and Composite Structure 11 (1): 21-38.

[13] Linzell, D. G., Hall, D., and White, D. 2004. "Historical Perspective on Horizontally Curved I-Girder Bridge Design in the United States." Journal of Bridge Engineering 9 (3): 218-29.

[14] Kim, C. W., and Kawatani, M. 2003. "End-Cross Beam Reinforcement against Traffic-Induced High-Frequency
Vibration of Steel Twin-Girder Bridge." Steel Structures 3: 261-70.

[15] Tan, G. H., Brameld, G. H., and Thambiratnam, D. P. 1998. "Development of an Analytical Model for Treating Bridge-Vehicle Interaction." Journal of Engineering Structure 20: 54-61.

[16] Wiss, J. F., and Parmelee, R. A. 1974. "Human Perception of Transient Vibration." Journal of Structural Division, ASCE 100: 773-87.

[17] Tolaymat, R. A. 1988. "A New Approach to Floor Vibration Analysis." Journal American Institute of Steel Construction, AISC 25 (4): 137-43.

[18] Murray, T. M., Allen, D. E., and Ungar, E. E. 1997. "Floor Vibration Due to Human Activity." In Steel Design Guide Series. Chicago: AISC (American Institute of Steel Construction).

[19] Smith, J. W. 1988. Vibration of Structures, Application in Civil Engineering Design. New York: Chapaman and Hall.

[20] ISO (International Organization for Standards). 1989. "Evaluation of Human Exposure to Whole-Body Vibration-Part 2: Continuous and Shock-Induced Vibration in Buildings ( 1 to $80 \mathrm{~Hz}$ )." In International Standard ISO-2631/2-1989(E). Geneva: ISO.

[21] AASHTO (American Association of State Highway and Transportation Officials). 2004. "Bridge Design Specifications." In AASHTO LRFD. Washington, D.C.: AASHTO.

[22] Wang, T. L., and Huang, D. 1992. Computer Modeling Analysis in Bridge Evaluation. Final Report-Highway Planning and Research Program, Miami, Florida, USA.

[23] Dodds, C. J., and Robson, J. D. 1973. "The Description of Road Surface Roughness." Journal of Sound and Vibration 31 (2): 175-83.

[24] Honda, H., Kajikawa, Y., and Kobori, T. 1982. "Spectra of Road Surface Roughness on Bridges." Journal of the Structural Division, ASCE 108: 1956-66.

[25] Sayers, M. W. 1988. Dynamic Terrain Inputs to Predict Structural Integrity of Ground Vehicles. Technical Report-Transportation Research Institute, University of Michigan.

[26] Simo, J. C., and Laursen, T. A. 1990. “An Augmented Lagrangian Treatment of Contact Problems Involving Friction." Computers \& Structures 42 (1): 97-116.

[27] Awall, M. R., and Hayashikawa, T. 2011. "Parametric Study on Dynamic Interaction of Horizontally Curved Twin I-Girder Bridges and a Moving Vehicle." Journal of Structural Engineering, JSCE 57A: 242-51. 